\title{
A Inclusão de Pessoas com Necessidades Especiais no Ensino Superior ${ }^{1}$ INCLUSION OF PEOPLE WITH SPECIAL NEEDS IN HighER EDUCATION
}

\author{
Ronaldo Queiroz de OLIVEIRA ${ }^{2}$ \\ Silvana Maria Barros de OLIVEIRA ${ }^{3}$ \\ Natália Almeida de OLIVEIRA ${ }^{4}$ \\ Maria Cristina Soares Figueiredo TREZZA ${ }^{5}$ \\ Iara Barbosa RAMOS ${ }^{6}$ \\ Daniel Antunes FREITAS ${ }^{7}$
}

\begin{abstract}
RESUMO: trata-se de uma revisão integrativa que objetivou analisar a produção científica sobre a educação inclusiva no ensino superior. Os dados foram coletados nas bases de dados Lilacs, Scielo, Cochrane, Medline e PubMed, entre os anos 2005 e 2014 , utilizando-se os descritores controlados Special Education, Education Higher, Mainstreaming Education e Disabled Personse e os descritores não controlados Educaçáo Especial, Educação Superior, Inclusão Educacional e Pessoas com Deficiência; Educación Superior, Propension Educación, Personas com Discapacidad. A amostra constituiu em 16 artigos. As publicaçóes sobre a educação inclusiva no ensino superior têm sido tênues, demonstrando que ainda há muito a avançar nesse assunto. Conclui-se que o tema educação inclusiva é mais estudado em relação às crianças; as atençôes dos estudiosos em relação a pessoas adultas com necessidades especiais envolvem mais a assistência em saúde e não a educação inclusiva no ensino superior.
\end{abstract}

PALAVRAS-CHAVE: Educação Especial. Educação Superior. Inclusão Educacional. Pessoas com Deficiência.

ABSTRACT: it is an integrative review that aimed to analyze the scientific literature on inclusive education in higher education. Data was collected in the following databases: Lilacs, SciELO, Cochrane, Medline and PubMed, between the years 2005 and 2014, using the controlled descriptors Special Education, Higher Education, Education and Mainstreaming Disabled Person and uncontrolled descriptors Special Education, Higher Education, Educational Inclusion and Persons with Disabilities; Educación Superior, Propension Educación, Personas com Discapacidad. The sample consisted of 16 articles. The publications on inclusive education in higher education has been tenuous, demonstrating that there is still much to advance in this issue. We conclude that the issue of inclusive education is more studied in relation to children; and that the attention of scholars regarding adults with special needs involves mostly health care and not inclusive education in higher education.

KEYWORDS: Special Education. Higher Education. Educational Inclusion. People with Disabilities.

\section{INTRODUÇÃo}

A educação inclusiva é entendida como o processo de inclusão de pessoas com necessidades especiais ou com distúrbios de aprendizagem na rede comum de ensino em todos os

\footnotetext{
${ }^{1}$ http://dx.doi.org/10.1590/S1413-65382216000200011

${ }^{2}$ Pós-graduando em Docência do Ensino Superior, Universidade Católica Dom Bosco/UCDB, Campo Grande, MS, Brasil. queiroliveira@yahoo.com.br

${ }^{3}$ Mestranda em Enfermagem pelo Programa de Pós-Graduação em Enfermagem da Universidade Federal de Alagoas, Maceió, AL, Brasil.sbarrosqta1@gmail.com

${ }^{4}$ Universidade Integrada Tiradentes/UNIT, Enfermagem, Maceió, AL, Brasil. natholiiveiraa@gmail.com

${ }^{5}$ Professora Doutora Associado da Escola de Enfermagem e Farmácia, ESENFAR da Universidade Federal de Alagoas/UFAL. Maceió, AL, Brasil. trezzacris@gmail.com

${ }^{6}$ Professora Mestre da Universidade Católica Dom Bosco. Campo Grande, MS, Brasil.enf.iararamos@gmail.com

${ }^{7}$ Doutor em Ciências da Saúde, Docente do Programa de Pós-Graduação em Enfermagem da Universidade Federal de Alagoas, Maceió, AL, Brasil. danielmestradounincor@yahoo.com.br
} 
seus graus (MRECH, 2001). Nesse sentido, a ideia de inclusão que se quer valorizar parte de uma filosofia que tanto reconhece quanto aceita e acolhe a diversidade em todos os aspectos da vida em comunidade (PEREIRA; SANTOS, 2009). Ao pensar no ensino superior, parte-se da sua finalidade como a educação que vai desde a estimulação da criação cultural ao estímulo do conhecimento dos problemas existentes no mundo, de modo a que venha a prestar serviços especializados à comunidade, estabelecendo com esta uma relação de reciprocidade (BRASIL, 2014).

O termo necessidades especiais engloba num sentido amplo todas as pessoas que são portadoras de alguma deficiência, seja esta, de ordem física, cognitiva, socioeconômico e/ou cultural, que interfiram na acessibilidade, à qual, o indivíduo tem direito de adquirir ou usufruir. É frequente encontrar nos artigos científicos e documentos oficiais termos como: Pessoas com deficiência e outras necessidades especiais; alunos/estudantes com deficiência; pessoas portadoras de deficiência; estudantes com limitação por deficiência; pessoas com necessidades educacionais especiais, dentre outros semelhantes. Esse estudo, ao tratar da inclusão no ensino superior optou de modo reflexivo, buscando destituir-se de qualquer risco de estereótipo ou preconceito, utilizar-se do termo pessoas ou alunos com necessidades especiais, atribuindo-o a qualquer indivíduo que careça de atenção quando se trata do acesso à universidade, buscando valorizar tais necessidades decorrentes de condições individuais, que são reconhecidas na maioria das vezes como deficiências.

A reflexão sobre a educação inclusiva no ensino superior descortina um cenário frequentemente marcado pela segregação, ainda que se intencione incluir. Prova disto, um estudo a esse respeito, mostra a importância de se investir nos aspectos impeditivos para sua realização. Aspectos que envolvem desde a estrutura arquitetônica da Instituição de ensino, as estratégias pedagógicas, bem como na percepção e atitudes dos educadores que incluem os professores universitários. As percepçóes dos professores na verdade se constituem como filtros na interpretação da realidade, o que determina e interfere no modo como se comportam em relação a inclusão de alunos com necessidades especiais em sala de aula (ANTUNES et al., 2013).

De qualquer modo, em se tratando da educação inclusiva no ensino superior, é indubitável que sua implementação depende primeiramente das condiçóes criadas pelas universidades para receber adequadamente seus alunos com necessidades especiais de modo a que estes sejam incluídos no processo educacional, seja qual for à necessidade que ele apresente (COSTA; SANTOS-JÚNIOR, 2013). Embora a maior parte das justificativas para a não educação inclusiva seja reportada a estrutura física das instituiçóes de ensino, os estudos também têm demonstrado que a maior barreira para a inclusão escolar parte do despreparo dos agentes educacionais, dos professores aos gestores que não possuem formação, nem mesmo capacitação para lidar com esses alunos portadores de necessidades especiais (GLAT; PLETSCH, 2010).

Não obstante, o que se nota atualmente, é que a maior parte dos professores não teve formação inicial e nem continuada para atender alunos com necessidades especiais. Esse fato só faz perdurar o problema da formação docente, inclusive dos professores dos cursos de licenciatura que por não terem sido preparados para lidarem com essa demanda, não ensinam outros professores, o que produz um giro na roda do ensino que sofre o despreparo para lidar com as necessidades educacionais especiais (REIS; EUFRÁSIO; BAZON, 2010). 
Ainda a este respeito, defende-se que a educação inclusiva implica num ensino adaptado às necessidades individuais que sugerem necessidades educacionais especiais e para tanto, os docentes devem ser instrumentalizados para atender com propriedade a cada demanda advinda do ensino a pessoas com necessidades especiais, desenvolvendo recursos, instrumentos e estratégias educacionais que facilitem a vida dessas pessoas (SANT'ANA, 2005). Ressalta-se, portanto, que independente das discussóes, a realidade da inclusão educativa nas instituiçóes de ensino superior depende de questóes concretas refletidas na prática, que exigem respostas e atitudes individuais e coletivas que não se encontram em documentos governamentais, livros ou manuais (FERRARI; SEKKEL, 2007).

Embora reconhecendo que a educação inclusiva é fruto de todo um processo histórico da humanidade, percebe-se que ainda há um despreparo dos indivíduos de um modo geral, para aceitar o "diferente", bem como para entender que sua visão das pessoas com necessidades especiais vai automaticamente refletir na socialização e desenvolvimento desses indivíduos em qualquer esfera da sociedade. Assim, cabe aos gestores e agentes educacionais, àqueles que movem às instituições de ensino superior preparar a universidade estruturalmente, arquitetonicamente, mas, principalmente preparar-se enquanto seres humanos, para atuarem como agentes de transformação social, ensinando pelo exemplo demonstrado na prática, como se devem receber indivíduos com necessidades especiais, numa inclusão educacional que traga frutos de inclusão na sociedade, na vida produtiva e no mercado de trabalho (COSTA; SANTOS-JÚNIOR, 2013).

$\mathrm{O}$ interesse por esse objeto de estudo, a saber: a educação inclusiva no ensino superior voltada a pessoas com necessidades especiais, emerge da vivência no campus universitário, na companhia de pessoas com deficiências no âmbito físico ou cognitivo o que remete à percepção de que muitas vezes há um dúplice despreparo da universidade, tanto no âmbito físico-estrutural, quanto no campo das habilidades dos docentes para atender às necessidades desses indivíduos rompendo com tudo o que rege as normativas de inclusão social no ensino de nível superior.

Destarte, a falta de inclusão de pessoas com necessidades especiais nas universidades perpetua o discurso incapaz de romper com as barreiras sociais, privilegiam o modelo biomédico enfatizando a necessidade especial como déficit do biologismo do indivíduo, segregando-o do acesso ao conhecimento sem, no entanto, assumir sua atitude discriminatória (NUNES et al., 2011). Diante dessas considerações, esse artigo objetiva: analisar a produção científica sobre a educação inclusiva no ensino superior. Para tanto, realizou-se uma revisão integrativa da literatura.

\section{Métodos}

Trata-se de uma revisão integrativa da literatura, que por sua amplitude permite a síntese de múltiplos estudos publicados, possibilitando generalizar conclusóes a respeito de uma área particular de estudo (MENDES; SILVEIRA; GALVÃO, 2008). Para o desenvolvimento da revisão integrativa foram percorridas as seis etapas: 1) Estabelecimento de hipótese ou questão de pesquisa; 2) Amostragem ou busca na literatura; 3) Categorização dos estudos; 4) Avaliação dos estudos incluídos na revisão; 5) Interpretação dos resultados; 6) Síntese do conhecimento ou apresentação da revisão; segundo proposto por Mendes, Silveira e Galvão (2008) com o fim de garantir o rigor metodológico do estudo. 
A hipótese proposta pelo estudo é de que se as Instituições de Ensino Superior (IES) não estão preparadas para a inclusão de pessoas com necessidades especiais assim, esses indivíduos encontram dificuldades para adentrarem as universidades fazendo parte do grupo de discentes. No intento em confirmar ou refutar essa hipótese, a busca na literatura foi realizada nas Bases de dados da Biblioteca Virtual em Saúde (BVS) nas fontes Literatura Latino-Americana e do Caribe em Ciências da Saúde (LILACS), Scientific Electronic Library Online (SCIELO), Cochrane library (COCHRANE) e Medical Literature Analysis and Retrieval System Online (MEDLINE); e no National Center for Biotechnology Information (NCBI) na fonte Publicaçóes Médicas (PUBMED) em junho de 2015.

Utilizou-se na busca, os descritores controlados Education Higher, Mainstreaming Education e Disabled Personse dos descritores não controlados Educação Superior, Inclusão Educacional e Pessoas com Deficiência; Educación Supeior, Propension Educación, Personas com Discapacidad, segundo os dados da BVS na base de consulta Descritores em Ciências da Saúde (DeCS). Um descritor controlado refere-se especificamente à área de ciências na saúde, com o fim de representar os assuntos dos documentos e para serem utilizados como ferramenta de busca de artigos científicos e documentos que propiciem a divulgação, ampliação e replicação de pesquisas. Assim, o DeCS consiste numa adaptação e ampliação do MeSH (Medical Subject Headings), vocabulário desenvolvido pela NLM (National Library of Medicine, dos EUA), estando disponível em três idiomas: português, espanhol e inglês, onde os descritores são distribuídos e organizados em categorias (BRASIL, 2009), metodologia que viabilizou essa revisão integrativa.

Os cruzamentos com os descritores possibilitou a elaboração de nove estratégias de busca, as quais foram adequadas seguindo as especificidades de cada base de dados. Vale destacar que o termo adotado por esse estudo "pessoas com necessidades especiais" não foi usado como um descritor, por não mostrar-se vinculado a nenhum artigo nas estratégias de busca dessa pesquisa nas bases de dados supracitadas. Os critérios de inclusão estabelecidos foram: artigos que abordem a temática da educação inclusiva de pessoas com necessidades especiais no ensino superior, disponíveis eletronicamente na íntegra. Excluíram-se, portanto, artigos que tratem de pessoas com necessidades especiais sem relação com a educação, repetidos nas bases de dados e publicados fora do último decênio. Foram encontrados 525 artigos, porém, a amostra final foi composta por 16 desses estudos.

A busca proporcionou analisar o estado da arte sobre pessoas com necessidades especiais e reforçou o desejo dos autores em realizar esse estudo visto que, a maioria dos artigos encontrados tratava de necessidades especiais no campo da assistência em saúde; outros tratavam de crianças e adolescentes com necessidades especiais do tipo físicas como cegueira, surdez ou paraplegia ou mesmo mental, relacionando-as à inclusão na escola infantil ou no ensino fundamental; e ainda, outros se referiam à adultos com necessidades especiais, porém, não relacionados à inclusão desse grupo minoritário no ensino superior como é o caso do objeto desse estudo.

Com referência a qualidade dos artigos da amostra final aplicou-se a classificação do nível de evidência proposto por Stillwell et al. (2010): I - Revisão sistemática ou metanálise; II - Ensaio clínico randomizado controlado; III - Ensaio clínico controlado sem randomização; IV - Caso controle ou estudo de coorte; V - Revisão sistemática de estudo qualitativo ou des- 
critivo; VI - Estudo qualitativo ou descritivo; VII - Artigo de opinião ou consenso de órgãos governamentais ou conselho de especialidades médicas.Os dados extraídos após leitura dos resumos e da leitura flutuante do corpo dos artigos foram apresentados em forma de sinopse descritiva em tabelas e quadros que incluem as informaçôes do nível de evidência e categorização segundo necessidades especiais reportadas como objetos de estudo. A Figura 1 apresenta a consolidação da construção da amostra pelas estratégias de busca dessa revisão.

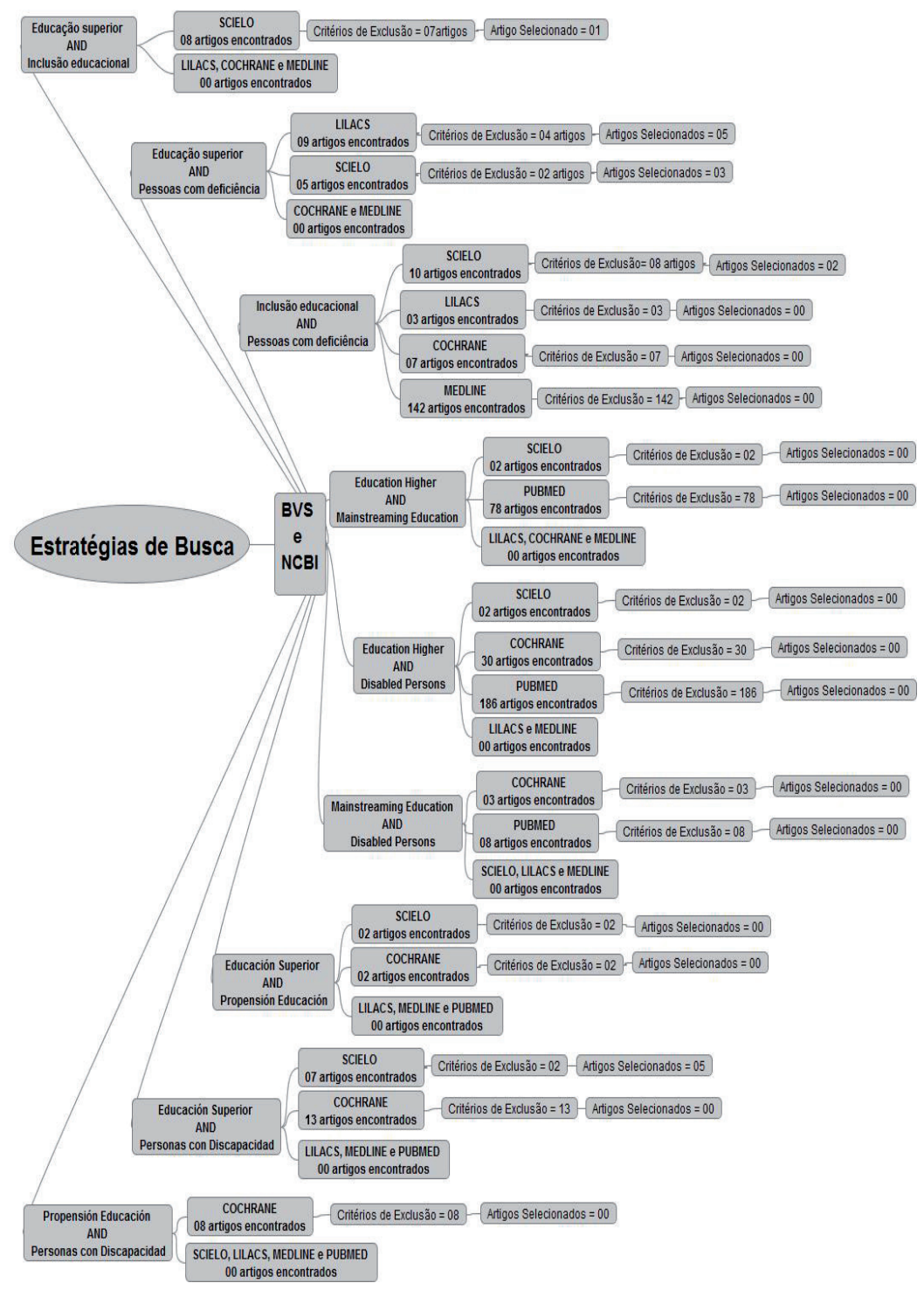

Figura 1 - Mapa Mental para representação gráfica da composição da amostra final de artigos revisados.

Fonte: elaboração própria. 
Os mapas mentais são ideais para agrupar e sintetizar e armazenar informaçóes que expressem de forma articulada as ideias do autor no formato de diagramas. Utilizou-se o programa de software FreeMind para a realização do mapa mental com o fim de viabilizar a visualização das estratégias de busca usadas nas bases de dados e o resultado dessas que culminaram na composição da amostra final. O software FreeMind é gratuitamente disponibilizado na mídia no endereço: <http://freemind.sourceforge.net/wiki/index.php/Download>.

\section{Resultados}

\subsection{CaracterizaÇáo dos estudos}

Referente à produção foi encontrado 525 artigos sobre pessoas com necessidades especiais nas bases LILACS 2,30\% ( $n=12)$, SCIELO 6,85\% ( $n=36)$, COCHRANE 12\% ( $n=63)$, MEDLINE 27,05\% (n=142) e PUBMED 51,80\% ( $n=272)$, porém, após leitura dos títulos, dos resumos e do corpo do texto, segundo critérios de exclusão, 3,04\% foi selecionado para essa revisão correspondendo à amostra final constituída por 16 estudos primários. Da amostra de 16 artigos, 68,75\% ( $n=11)$ constavam da base de dados SCIELO e os outros 31,25\% ( $n=5)$ foram selecionados na LILACS. Não houve artigos selecionados por essa revisão nas bases COCHRANE, MEDLINE e PUBMED já que os estudos tratavam de crianças com necessidades especiais relacionados à educação básica, ou tratavam de adultos e crianças com essas necessidades, voltados à assistência em saúde diferente do objeto de estudo proposto por essa revisão.

Com referência aos países de publicação dos estudos, que compuseram a amostra $(\mathrm{n}=16)$, houve predominância de artigos originados no Brasil, em 62,5\% ( $\mathrm{n}=10)$; seguido pela Colômbia com 18,75\% (n=3); México com 12,5\% (n=2) e Portugal com apenas 6,25\% (n=1). Como frequentemente a produção científica está relacionada ao envolvimento de autores vinculados ao ensino e pesquisa nas universidades, a formação profissional dos autores $(n=41)$ e a análise das Instituições de Ensino Superior (IES) onde eles possuíam vínculo profissional ou educacional é demonstrada consecutivamente nas Tabelas 1 e 2 .

Tabela 1 - Autores dos artigos revisados, segundo Formação.

\begin{tabular}{lcc}
\hline Formaçáo Profissional & $\mathbf{n}$ & $\mathbf{\%}$ \\
\hline Psicólogo & 15 & 36,58 \\
Educador Físico & 5 & 12,19 \\
Fonoaudiólogo & 5 & 12,19 \\
Enfermeiro & 3 & 7,33 \\
Terapeuta Ocupacional & 2 & 4,87 \\
Administrador & 1 & 2,44 \\
Desenhista & 1 & 2,44 \\
Engenheiro & 1 & 2,44 \\
Filósofo & 1 & 2,44 \\
Licenciado em Ciências da Educação & 1 & 2,44 \\
Licenciado em Idiomas & 1 & 2,44 \\
Licenciado em Letras Anglo Portuguesas & 1 & 2,44 \\
Médico & 1 & 2,44 \\
Pedagogo & 1 & 2,44 \\
Técnico Administrativo & 1 & 2,44 \\
Técnico em Recursos Humanos & 1 & 2,44 \\
\hline Total & 41 & 100 \\
\hline
\end{tabular}

Fonte: Elaboração própria. 
Cabe ressaltar, que para os casos nos quais, os autores possuíam vínculo profissional e educacional reportados em instituiçóes distintas, priorizou-se nesse estudo, o vínculo profissional, que em sua maioria referia-se as atividades de docência no ensino superior. A Tabela 2 apresenta a distribuição dos autores dos artigos revisados, segundo o vínculo com as IES e a localização demográfica correspondente a essas instituiçóes.

Tabela 2 - Distribuição dos autores, segundo vínculo com as IES e localização demográfica.

\begin{tabular}{|c|c|c|c|c|}
\hline \multirow{2}{*}{$\begin{array}{l}\text { Localizaçáo } \\
\text { Demográfica }\end{array}$} & IES & SIGLA & $\mathbf{n}$ & $\%$ \\
\hline & \multicolumn{4}{|l|}{ BRASIL } \\
\hline \multirow{9}{*}{ Sudeste } & Universidade de São Paulo - Campus Bauru & USP Bauru & 6 & 14,55 \\
\hline & Universidade Federal de Juiz de Fora & UFJF & 5 & 12,19 \\
\hline & Pontifícia Universidade Católica de Campinas & PUC Campinas & 4 & 9,79 \\
\hline & Universidade Federal de São Carlos & UFSCar & 3 & 7,33 \\
\hline & Universidade de São Paulo & USP & 3 & 7,33 \\
\hline & Universidade Estadual de Campinas & UNICAMP & 1 & 2,44 \\
\hline & Universidade Presbiteriana Mackenzie (São Paulo) & UPM & 1 & 2,44 \\
\hline & Universidade do Estado do Rio de Janeiro & UERJ & 1 & 2,44 \\
\hline & Universidade Federal Fluminense & UFF & 1 & 2,44 \\
\hline Nordeste & Universidade Estadual do Sudoeste da Bahia - Jequié & UESB & 1 & 2,44 \\
\hline \multirow[t]{2}{*}{ Sul } & Universidade Federal de Santa Maria & UFSM & 1 & 2,44 \\
\hline & OUTROS PAÍSES & & & \\
\hline Portugal & Universidade do Minho - (Braga) & UMinho & 4 & 9,79 \\
\hline \multirow[t]{2}{*}{ Colômbia } & Universidad de La Sabana - (Bogotá) & UniSabana & 3 & 7,33 \\
\hline & Universidad Del Rosario - (Bogotá) & URosario & 2 & 4,87 \\
\hline \multirow[t]{3}{*}{ México } & Universidad Juárez Autônoma de Tabasco & UJAT & 3 & 7,33 \\
\hline & Universidad Nacional Autônoma de México & UNAM & 2 & 4,87 \\
\hline & & Total & 41 & 100 \\
\hline
\end{tabular}

Fonte: Elaboração própria. 
A caracterização da amostra conforme ano de publicação dos estudos é apresentado na Tabela 3 .

Tabela 3 - Distribuição de artigos sobre a educação inclusiva segundo ano de publicação.

\begin{tabular}{lcc}
\hline Ano de Publicaçáo & n & $\%$ \\
\hline 2005 & 0 & 0 \\
2006 & 2 & 12,5 \\
2007 & 1 & 6,25 \\
2008 & 1 & 6,25 \\
2009 & 1 & 6,25 \\
2010 & 2 & 12,5 \\
2011 & 2 & 12,5 \\
2012 & 1 & 6,25 \\
2013 & 4 & 25,0 \\
2014 & 2 & 12,5 \\
\hline Total & 16 & 100 \\
\hline
\end{tabular}

Fonte: Elaboração própria.

Com relação ao delineamento metodológico dos estudos, a Tabela 4, apresenta o tipo de pesquisa originária dos artigos, a técnica de pesquisa utilizada e o nível de evidência segundo proposto por Stillwell et al. (2010).

Tabela 4 - Distribuição segundo delineamento e nível de evidência dos estudos $(n=11)$.

\begin{tabular}{lccc}
\hline Delineamento do Estudo & Nível de Evidência & $\mathbf{n}$ & $\mathbf{\%}$ \\
\hline Revisão Sistemática & I & 0 & 0 \\
Ensaio Controlado Randomizado & II & 1 & 6,25 \\
Ensaio Controlado Não Randomizado & III & 0 & 0 \\
Caso Controle ou Estudo de Coorte & IV & 5 & 31,25 \\
Revisão Sistemática de Estudo Qualitativo ou Descritivo & V & 2 & 12,5 \\
Estudo Qualitativo ou Descritivo & VI & 8 & 50,0 \\
Artigo de Opinião ou Consensode Órgãos Governamentais ou & VII & 0 & 0 \\
Conselho de Especialidades Médicas & Total & $\mathbf{1 6}$ & $\mathbf{1 0 0}$ \\
\hline
\end{tabular}

Fonte: Elaboraçáo própria.

Com referência à técnica utilizada na pesquisa originária dos estudos revisados ( $n=16)$, predominou a análise de conteúdo em 43,75\% ( $n=7)$; seguido por entrevista 37,5\% $(\mathrm{n}=6)$; questionário em $12,5 \%(\mathrm{n}=2)$ e desenho-estória com tema, na minoria de 6,25\% ( $\mathrm{n}=1)$ dos estudos. $\mathrm{Na}$ busca por analisar o tipo de necessidades especiais que foram objeto de estudo correspondente aos artigos, observa-se que a maioria das pesquisas não discriminava o tipo dessas necessidades, abrangendo todas as necessidades especiais no âmbito físico ou mental, 
culminando em 81,25\% ( $n=13)$; outros 12,5\% $(n=2)$ tratavam deficiências no campo visual seja cegueira ou baixa acuidade visual e por fim, a minoria de $6,25 \%(n=1)$ correspondente ao déficit auditivo ou surdez completa.

A respeito da titulação dos autores $(n=41)$ conforme informado nos artigos, predominou o nível acadêmico de Doutores em cerca de 29,15\% ( $\mathrm{n}=12)$; seguido por 19,51\% ( $\mathrm{n}=8)$ de Mestres; Doutorandos, Mestrandos e Graduados foram encontrados na mesma proporção de 9,79\% (n=4) respectivamente, num total de 12 autores correspondente à 29, 37\%; ainda Pós-Doutor em 7,33\% (n=3) e igualmente o Nível Técnico com 7,33\% (n=3) autores; em menor número apresentaram-se 4,87\% $(n=2)$ de Pós-Graduados Latu Senso e apenas 2,44\% $(\mathrm{n}=1)$ Pós-graduando no mesmo nível educacional. Vale ressaltar, que desses autores $(\mathrm{n}=41)$ a maioria 53,65\% ( $\mathrm{n}=22)$ informaram estarem exercendo suas atividades profissionais como Docentes do Ensino Superior.

\subsection{Categorizaçáo temática}

A leitura textual dos artigos proporcionou categorizar os estudos com relação às abordagens temáticas realizada pelos autores-pesquisadores referente a pessoas com necessidades especiais e a inclusão no ensino superior. Essas categorias refletem as concepçóes, áreas de interesse em investigaçóes e intervenções com o fim de possibilitar a inclusão sócio educacional de indivíduos portadores de necessidades especiais nas IES. Assim cinco áreas temáticas foram evidenciadas e aqui ressignificadas pelos autores desse estudo como:

\subsubsection{Padróes nORMATIVOS E ORgANiZACIONAIS DAS IES COMO DETERMinANTES ATITUdiNAIS}

Essa foi a temática mais fomentada por 62,5\% $(\mathrm{n}=10)$ estudos (NUNES et al., 2011; RUSSO; COUTO; VAISBERG, 2009; FERRARI; SEKKEL, 2007; LOPES; FARO, 2006; OLIVEIRA, 2013; CASTRO; ALMEIDA, 2014; DUARTE et al., 2013; SQUARCINI; ESTEVES, 2013; BÉJAR, 2010; PADILLA; SARMIENTO; COY, 2013). Segundo esses estudos, a atitude dos funcionários e docentes das IES é um reflexo das normas institucionais e do direcionamento da gestão no trato das pessoas com tais necessidades educacionais especiais.

\subsubsection{COMPARAÇÃo ENTRE LEGISLAÇÃO, DisCURSO POLÍTICO E PRÁTICA SOCIAL}

Nessa categoria temática 56,25\% $(\mathrm{n}=9)$ dos estudos (NUNES et al., 2011; OLIVEIRA, 2013; SIQUEIRA; SANTANA, 2010; (DUARTE et al., 2013; SANTUÁRIO; CAZALES, 2014; BÉJAR, 2006, 2010; PADILLA; SARMIENTO; COY, 2013; ZÚNIGA; MARTÍNEZ; IZQUIERDO, 2012), fizeram estudos comparativos que contrapunham os documentos governamentais e legislativos com a prática da sociedade acadêmica e os discursos políticos referentes à inclusão de pessoas com necessidades especiais no ensino superior.

\subsubsection{PERFIL E FORMAÇÃO dOS DOCENTES DO ENSINO SUPERIOR}

Seis trabalhos tiveram essa temática abordada em suas pesquisas, defendendo que a assistência docente à pessoas com necessidades especiais carece de investimentos na formação profissional especial, para atender as demandas do ensino superior à essas pessoas com as especi- 
ficidades decorrentes de suas deficiências (LACERDA; GURGEL, 2011; FERRARI; SEKKEL, 2007; LOPES; FARO, 2006; CASTRO; ALMEIDA, 2014; SQUARCINI; ESTEVES, 2013; BÉJAR, 2006).

\subsubsection{Condicionantes do AMBIENTE Físico}

A preocupação com as condiçóes do entorno das universidades como fator determinante para a inclusão ou exclusão de pessoas com necessidades especiais no ensino superior foi reportada em 37,5\% ( $n=5)$ : Lamônica et al. (2008); Lopes e Faro (2006); Castro e Almeida (2014); Béjar (2010); Zúñiga, Martínez e Izquierdo (2012) e o caráter investigativo predominou resultando em intervençóes para o conserto das debilidades físicas estruturais das IES.

\subsubsection{Fisiopatologia DAS DEFICIÊNCIAS COMO BARREIRA}

Nesse campo de investigação apenas um artigo foi encontrado, correspondendo a $6,25 \%$ da amostra. Os autores tratavam da cronobiologia de deficientes visuais como carentes de atenção por parte das IES para suplantar as dificuldades que emergem dessa necessidade especial, ressaltando a necessidade de parceria com as instituiçóes de assistência à saúde.

\section{DiscuSSÃo}

Ao analisar o total da produção encontrada nas bases de dados sobre as pessoas com necessidades especiais, observa-se que a maioria dos estudos tratava dessas necessidades como um problema de saúde desvinculando o individuo com essas deficiências, do contexto educacional. Embora 05 bases de dados (SCIELO, LILACS, COCHRANE, MEDLINE e PUBMED) tenham sido consultadas nessa revisão, os artigos selecionados partiram das bases de dados LILACS e SCIELO e provavelmente essa casuística se deve ao escopo das bases consultadas, relacionado à ciências da saúde. Infere-se, portanto, que em se consultando bases de dados específicas da área de educação, provavelmente, um maior acervo sobre a educação inclusiva de pessoas com necessidades especiais será encontrado.

Da amostra $(n=16)$ revisada verificou-se que a maioria 56,25\% ( $n=9)$ tratava-se de artigos originais (LACERDA; GURGEL, 2011; RUSSO; COUTO; VAISBERG, 2009; LAMÔNICA et al., 2008; LOPES; FARO, 2006; OLIVEIRA, 2013; CASTRO; ALMEIDA, 2014; DUARTE et al., 2013; BÉJAR, 2010; ZÚNIGA; MARTÍNEZ; IZQUIERDO, 2012), validando essa revisão integrativa, partindo da premissa de que esse método é ideal para reunir pesquisas publicadas que tratem de determinado objeto de estudo, analisar sistematicamente seus resultados de maneira ordenada, sintetizando as evidências disponíveis, tendo como produtos finais, o estado atual do conhecimento e a identificação de lacunas que direcionam a realização de novos estudos e intervençóes (MENDES; SILVEIRA; GALVÁO, 2008).

No processo histórico nacional e internacional houve uma transformação crescente no paradigma da inclusão social. Vários marcos legais, políticos e pedagógicos têm sido os causadores dessas mudanças evolutivas. Em se tratando da inclusão de pessoas com necessidades especiais na educação superior do cenário brasileiro, destaca-se o Programa Incluir do Ministério da Educação, que no período de 2005 a 2011visou promovera acessibilidade na 
educação superior por meio de chamadas públicas concorrenciais, que significaram o início da formulação de estratégias para identificação das barreiras refletidas no acesso das pessoas com deficiência no ensino superior (BRASIL, 2013, 2007). Infere-se que em virtude da disseminação dessa política pública, as pesquisas sobre essa temática começaram a partir de 2006, semelhantemente aos achados nessa revisão.

Observou-se que o perfil dos autores relacionado à formação profissional foi diversificado, porém, houve predominância de psicólogos 36,58 $(n=15)$ o que demonstra um maior interesse nas pessoas com necessidades especiais no contexto universitário, defendendo tais necessidades enquanto característica da diversidade humana (NUNES et al., 2011). No entanto, outras profissóes foram contempladas dadas as multiplicidades de demandas decorrentes da atenção educacional especial.

Relacionado à distribuiçãao geográfica das publicações, a maioria foi desenvolvida por pesquisadores da região Sudeste do Brasil 60,95\% (n=25) vinculados à IES do estado de São Paulo, Rio de Janeiro e Minas Gerais, significando mais da metade do contingente de autores desse estudo de modo que, esses dados podem estar relacionados ao desenvolvimento socioeconômico dessa região, refletindo-se em maior número de IES além, de mais recursos e fomento para as pesquisas; corroborando com o padrão regional de pesquisas em saúde definido por Guimarães (2011), como mais expressas no sudeste brasileiro. Nessa revisão, seguiu-se a regiáo Nordeste com 2,44\% $(n=1)$, o mesmo que a região Sul, com o menor número de publicações em ambas as regiōes. Também foram encontrados vários estudos nos quais os autores têm origens internacionais $(\mathrm{n}=14)$, sendo $12,19 \%(\mathrm{n}=5)$ advindos do México, igualmente da Colômbia, e 9,79\% (n=4) de Portugal.

Diante dos achados a análise das categorias temáticas elencadas nos artigos passou por uma ressignificação dos autores como facilitador da descrição dos resultados, e nessa investigação observou-se uma maior atenção à temática dos padrôes normativos e organizacionais das IES como determinantes atitudinais ressaltando o papel da universidade em estabelecer um padrão organizacional includente voltado a esses indivíduos. Segundo Nunes et al. (2011) a essa altura do contexto histórico social, torna-se imperdoável à sociedade de um modo geral, enxergar de forma estigmatizada uma deficiência ou desabilidade, ainda mais, em se tratando das universidades, que por significarem espaços culturais e educativos têm a imperância de basear-se no discurso que eleja as deficiências como contributos para a diversidade valoral das expressóes humanas.

Ainda segundo esses autores (NUNES et al., 2011; RUSSO; COUTO; VAISBERG, 2009; FERRARI; SEKKEL, 2007; LOPES; FARO, 2006; OLIVEIRA, 2013; CASTRO; ALMEIDA, 2014; DUARTE et al., 2013; SQUARCINI; ESTEVES, 2013; BÉJAR, 2010; PADILLA; SARMIENTO; COY, 2013), a inclusão de pessoas com necessidades espaciais nas IES, perpassa o pessoal e depende intrinsicamente do discurso adotado pelas universidades de modo que, se por um lado, utiliza-se de eufemismos para lidar com o "diferente" na estrutura organizacional das IES, gera-se simplesmente uma redoma de sentimentos de compaixáo e perpetua-se a marginalização mascarada de bondade, relacionado aos alunos com necessidades especiais, reproduzindo entre os gestores, docentes, discentes e funcionários atitudes discrimi- 
natórias frente a esse grupo minoritário que segundo à legislação vigente tem total direito de acesso à educação superior.

Dessa feita, se a IES tiver por filosofia as deficiências como um problema impossível de ser tratado, perdurarão esses achados, e a exclusão paulatinamente será expressa por seus constituintes gestores, professores, alunos e funcionários. Essas consideraçóes remetem a reflexão quanto a próxima categoria encontrada onde os estudos fizeram comparaçóes entre a legislação vigente em seus respectivos países, o discurso político e prática social dentro das IES.

A comparação entre legislação, discurso político e prática referida pelos autores (NUNES et al., 2011; OLIVEIRA, 2013; SIQUEIRA; SANTANA, 2010; DUARTE et al., 2013; SANTUÁRIO; CAZALES, 2014; BÉJAR, 2006, 2010; PADILLA; SARMIENTO; COY, 2013; ZÚNIGA; MARTÍNEZ; IZQUIERDO, 2012), seguiu os documentos governamentais e legislativos do país originário das publicaçóes. Exemplo disto, uma pesquisa realizada num município de Minas Gerais, analisou as políticas públicas implementadas pelo Governo Federal Brasileiro relacionado ao acesso de pessoas com necessidades especiais no ensino superior, como o ProUni, o REUNI e o FIES, comparando-os com o número de alunos autodeclarados com essas necessidades especiais nas instituiçôes públicas e privadas, e concluiu que as IES privadas possuíam um maior índice $82,2 \%$ de discentes com necessidades especiais matriculados, em detrimento do setor público educacional com apenas 17,8\% (DUARTE et al., 2013).

As preocupações em validar na prática, a inclusão de pessoas com necessidades especiais no ensino superior, também é demonstrada nessa revisão por estudos internacionais. Um desses estudos (SANTUÁRIO; CAZALES, 2014), realizados no México, analisou o marco normativo para a equidade nas políticas do país, especialmente as dirigidas à educação superior, defendendo a igualdade de oportunidades como igualdade de capacidades para atuar na sociedade, inclusive como entes participativos na eleição dos gestores políticos e acadêmicos. Segundo Santuário e Cazales (2014), isto difere dos sistemas onde as iniquidades educativas são reproduzidas, consequentemente contribuindo para as iniquidades sociais, o que só poderá ser corrigido, se o sistema educativo tiver a qualidade de acesso democrático e o apoio para que qualquer cidadão possa aproveitar igualmente das oportunidades advindas do ensino superior.

Acredita-se, que os docentes são os maiores mediadores da inclusão de pessoas com necessidades especiais nas salas de aula do ensino superior, porém, o despreparo e o tradicionalismo podem ser impeditivos para que essa inclusão aconteça tanto nos espaços sociais, quanto educacionais (OLIVEIRA, 2013). E dessa observação, emerge a temática do perfil e formação dos docentes do ensino superior para atender as demandas especiais de seus alunos.

A esse respeito, um estudo brasileiro (CASTRO; ALMEIDA, 2014) realizado com 13 universidades que possuíam mais de 20 alunos com necessidades especiais regularmente matriculados, entrevistou coordenadores de serviços especializados no atendimento desses alunos, e os próprios alunos com deficiências variadas como, deficiência visual, física e surdez, elucidaram em suas entrevistas as barreiras pedagógicas para a inclusão nas IES, nomeadamente como a ação docente. Segundo eles, a falta de capacitação é expressa pela didática inapropriada na sala de aula, pelos materiais empregados e pela incapacidade de adaptá-los às necessidades especiais. 
Cabe aqui a reflexão quanto a essa formação dos docentes universitários, pois, questiona-se se esses profissionais, independente da área em que se formaram, foram preparados para atuarem na academia da educação para as diferenças. Segundo Ferrari e Sekkel (2007) é preciso rever a importância da formação docente e considerá-la como uma exigência diante dos desafios da educação inclusiva, visto que, a competência técnica não garante a condição de reconhecer e ser capaz de trabalhar com as diferenças em direção a uma sociedade educativa emancipatória. Nesse sentido, a exemplo da Colômbia (BÉJAR, 2006), faz-se necessário uma atenção na reorganização dos currículos políticos pedagógicos, proporcionando suplantar os fatores que se constituem como barreiras para o desenvolvimento de pessoas com necessidades especiais nas universidades, e para tanto, precisa-se extrapolar alguns pressupostos na formação docente, renovando os modos de se preparar para atender a diversidade que inclui as necessidades especiais do alunado.

Somado à formação dos professores, outra categoria temática foi foco de investigação de alguns autores (LAMÔNICA et al., 2008; LOPES; FARO, 2006; CASTRO; ALMEIDA, 2014; BÉJAR, 2010; ZÚNIGA; MARTÍNEZ; IZQUIERDO, 2012) desse estudo, como os condicionantes do ambiente físico para a inclusão de pessoas com necessidades especiais nos espaços do ensino superior. Segundo a lei n. ${ }^{\circ} 10.098$ de 19 de dezembro de 2000, publicada no Diário Oficial da União, as universidades brasileiras têm a obrigação legal de realizarem adaptaçóes em seu ambiente físico e de equiparem seus prédios com estrutura capaz de suprir todas as necessidades dos alunos com necessidades especiais em seu campus (BRASIL, 2000). Necessita-se para tanto transformar a visão quanto a essas necessidades especiais, pois, a generalização das mesmas, tende a desvalorização das especificidades, imprescindível na efetivação da inclusão social e educativa (LOPES; FARO, 2006).

Pode-se dizer, que a despeito dos marcos legais existentes para a educação inclusiva, as ações institucionais voltadas a pessoas com necessidades especiais ainda são tênues e frágeis. Segundo sugere Béjar (2010) é importante se promover uma cultura em respeito a diversidade, reconhecendo os alunos com necessidades especiais como sujeitos, membros participativos da sociedade como um todo, a fim de transformar as concepçóes dos que compóem os cenários educativos. Atentar aos detalhes do ambiente físico pode ser a saída para o rompimento desse fator como barreira de acessibilidade às universidades como: rampas em todo o campus, pisos assentados niveladamente e antiderrapantes, sinalizaçóes em múltiplas linguagens, como em braile e na língua brasileira de sinais, salas de aula amplas, com espaço para cadeiras de rodas, enfim, apoiar-se no conhecimento das necessidades especiais individuais, para acabar com a segregação desses indivíduos permitindo efetivamente uma educação universitária inclusiva (LOPES; FARO, 2006).

Ainda como essencial para a educação inclusiva, surgiu nessa revisão a atenção dos autores (SQUARCINI; STEVES, 2013) à fisiopatologia das necessidades especiais que podem interferir direta ou indiretamente no acesso ou na permanência de pessoas com necessidades especiais específicas como a visão. Segundo esses autores a cronobiologia é a ciência que estuda como os seres vivos organizam sua estrutura temporal. Em se tratando de alunos totalmente cegos, o ritmo circadiano expressa um padrão livre-curso, de modo que o relógio biológico apresenta período endógeno diferente de 24 horas, e nesse caso, o organismo se encontra em desconformidade com o ambiente dando origem aos problemas sociais, inclusive na aprendizagem que são afetadas pelos sintomas de sonolência excessiva durante o dia, queda no alerta, distúrbios de humor causados pela insônia noturna (SQUARCINI; STEVES, 2013). 
A importância do conhecimento dos professores e gestores dessas especificidades fisiológicas contribuirá para o atendimento dessas necessidades pelo estabelecimento de parcerias com instituiçóes de saúde especializadas em sono, capazes de intervir no ritmo circadiano, com medidas simples, como a prescrição de melatonina na forma de medicamentos, suprindo o déficit desse hormônio no organismo, que é o controlador do ritmo circadiano.

Embora as IES venham se transformando acompanhando o processo histórico e as mudanças das demandas sociais, ao longo do tempo, ainda são muitos os desafios para que de uma vez por todas, as universidades se posicionem de maneira incisiva e assertiva na direção da inclusão de pessoas com necessidades especiais no ensino superior. Dessa feita, num processo evolutivo e dinâmico, pouco a pouco se estabelecerá uma melhora cultural no trato desses indivíduos com necessidades especiais.

\section{Conclusão}

A análise da produção científica sobre a educação inclusiva no ensino superior, objetivo desse estudo, proporcionou uma reflexão quanto à atenção que tem sido dada à diversidade de pessoas com necessidades especiais no ensino superior. Observa-se que para as açóes educativas de inclusão e a complexidade dessas questóes, pressupóe-se que as discussóes ainda não estão prontas e não se encerram em si mesmas, mas sim, estão sendo construídas e transformadas à medida que se avança no conhecimento das realidades e reais necessidades das pessoas com necessidades especiais, para que sejam efetivamente inclusas com igualdade e plenitude nas universidades.

Conclui-se, portanto, que as produções sobre o tema da educação inclusiva no ensino superior, são tênues, comparadas à complexidade da questão, principalmente no que concerne à prática inclusiva em si, diante das normalizaçóes e legislações governamentais. E ainda, que o tema da educaçáo inclusiva é mais estudado em relaçáo às crianças, ou quando as atençóes dos estudiosos são voltadas a pessoas adultas e crianças com necessidades especiais, envolve mais a assistência em saúde e não a educação inclusiva no ensino superior.

Ao que parece, as universidades caminham a passos lentos no avanço do conhecimento das especificidades das necessidades especiais de seus alunos e por essa razão, não suprem de forma integral as carências competitivas para a inclusão educacional. É preciso apreender o conhecimento de que a necessidade especial de uma pessoa não pode reduzir seus direitos enquanto cidadãos de uma nação, que tem por obrigação promover assistência igualitária em todos os âmbitos da vida humana.

Assim, perdura-se o desconhecimento colocando as universidades numa falsa posição de conforto quanto aos seus deveres legais, já que a reserva de vagas para alunos com necessidades especiais lhes parecem ser em si, a referida inclusão social e educativa desses indivíduos. Infelizmente, os prejuízos do desconhecimento se refletem dentro das unidades universitárias ao longo do país e do mundo, perpetuando o preconceito e leituras estereotipadas das necessidades especiais, o que culmina na violação do direito de ser diferente e ao mesmo tempo, de se ter direito igualitário de acesso a inúmeras experiências dentro do universo que se reproduz nas universidades.

Sugere-se que novos diálogos sejam feitos entre representantes legais, comunidade, gestores, professores e corpo discente dos campos educativos, incluindo às universidades, ou- 
vindo seus alunos com necessidades especiais, numa concatenação de ideias entre as diversas áreas de conhecimento, para que se obtenha a compreensão das dimensóes que envolvem a inclusáo de pessoas com necessidades especiais nos cenários educativos, realizando também novas pesquisas que possibilitem fechar as lacunas do conhecimento que limitam a açáo efetiva na inclusão social e educativa de pessoas com necessidades especiais.

\section{REFERÊNCIAS}

ANTUNES, A.P. et al. Inclusão no ensino superior: percepções de professores em uma universidade portuguesa. Rev. Psicologia em Pesquisa, Portugal, v.7, n.2, p.140-150, 2013.

BÉJAR, R.M. Educación superior para estudiantes com discapacidad. Revista de Investigación, Caracas, v.34, n.70, p.1-9, 2010.

BÉJAR, R.M. Hacia uma educación com igualdad de oportunidades para personas condiscapacidad. Rev. Fac. Med. Univ. Nac. da Colômbia, Colômbia, v.54, n.2, p.148-154, 2006.

BRASIL. Câmara dos Deputados. Lei das Diretrizes e Bases da Educação Nacional - LDB: Lei no 9.394 de 1996. 9. ed. Brasília, DF: Câmara dos Deputados, Ediçôes Câmara, 2014.

BRASIL. Ministério da Educação. Programa incluir: acessibilidade na educação superior. Documento orientador. Brasília, DF: SECADI/SESu, 2013. Disponível em: <http://portal.mec.gov.br/index. php?option=com_docman\&view=download\&alias=12737-documento-orientador-programa-incluirpdf\&category_slug=marco-2013-pdf\&Itemid=30192>. Acesso em: 16 jun. 2015.

BRASIL. Ministério da Educaçấo. Secretaria de Educaçáo Especial. Secretaria de Educação Superior. Edital n. ${ }^{\circ}$ 3, de 26 de Abril de 2007. Programa Incluir: acessibilidade na educaçáo superior. Braśília, DF: SEESP/SESU, 2007. Disponível em: <http://portal.mec.gov.br/sesu/arquivos/pdf/editalincluir_ mec.pdf>. Acesso em: 16 jun. 2015.

BRASIL. Câmara dos Deputados. Lei no 0.098, de 19 de dezembro de 2000. Lei da Acessibilidade. Brasília, DF, 2000. Disponível em: <http://www2.camara.leg.br/legin/fed/lei/2000/lei-10098-19dezembro-2000-377651-normaatualizada-pl.pdf>. Acesso em: 14 jun. 2015.

BRASIL. Biblioteca Virtual em Saúde/BIREME. Tutorial de pesquisa bibliográfica. São Paulo, 2009.

CASTRO, S.F.; ALMEIDA, M.A. Ingresso e permanência de alunos com deficiência em universidades públicas brasileiras. Rev. Bras. Educ. Espec., Marília, v.20, n.2, p.179-194, 2014.

COSTA, A.E.; SANTOS-JÚNIOR, C.L. Necessidades especiais no ensino superior: inclusão ou exclusão? Rev. Fragmentos de Cultura, Goiânia, v.23, n.2, p.185-194, 2013.

DUARTE, E.R. et al. Estudo de caso sobre a inclusão de alunos com deficiência no ensino superior. Rev. Bras. Educ. Espec., Marília, v.19, n.2, p.289-300, 2013.

FERRARI, M.A.L.D.; SEKKEL, C. Educação inclusiva no ensino superior: um novo desafio. Psicologia Ciência e Profissäo, Brasília, DF, v.27, n.4, p.636-647, 2007.

GLAT, R.; PLETSCH, M.D. O papel da universidade no contexto da política de educaçáo inclusiva: reflexōes sobre a formação de recursos humanos e a produção do conhecimento. Rev. Educ. Especial, Santa Maria, v.23, n.38, p.345-356, 2010.

GUIMARÃES, R. Desafios da pós-graduação em saúde humana no Brasil. Rev. Saúde Pública, São Paulo, v.45, n.1, p.1-12, 2011. 
LACERDA, C.B.F.; GURGEL, T.M.A. Perfil de tradutores-intérpretes de libras (TILS) que atuam no ensino superior no Brasil. Rev. Bras. Educ. Espec., Marília, v.17, n.3, p.481-496, 2011.

LAMÔNICA, D.C. et al. Acessibilidade em ambiente universitário: identificação de barreiras arquitetônicas no campus da USP de Bauru. Rev. Bras. Educ. Espec., Marília, v.14, n.2, p.117-188, 2008.

LOPES, M.J.; FARO, A.C.M. Deficiências e educação inclusiva. O mundo da saúde, São Paulo, v.30, n.1, p.45-51, 2006.

MENDES, K.D.S.; SILVEIRA, R.C.C.P.; GALVÃO, C.M. Revisão integrativa: método de pesquisa para a incorporação de evidências na saúde e na enfermagem. Texto \& Contexto Enferm., São Paulo, v.17, n.4, p.758-764, 2008.

MRECH, L.M. O que é educação inclusiva. Educação on-line. 2001. Disponível em: <http://www. educacaoonline.pro.br/index.php?option=com_content \&view=article\&id=107:o-que-e-educacaoinclusiva\&catid=6:educacao-inclusiva\&Itemid=17>. Acesso em: 07 jun. 2015.

NUNES, T. et al. Perspectiva social sobre os discursos opressores da deficiência na universidade. Psico, Porto Alegre, Rio Grande do Sul, v.42, n.1, p.123-133, 2011.

OLIVEIRA, C.B. Jovens deficientes na universidade: experiências de acessibilidades? Rev. Bras. De Educaçâo, Niterói, v.18, n.55, p.961-1065, 2013.

PADILLA, E.M.; SARMIENTO, P.J.; COY, L.Y. Educación inclusiva y diversidade funcional em la universidad. Revista de la facultad de medicina, Bogotá, v.61, n.2, p.1-30, 2013.

PEREIRA, C.L.; SANTOS, M. Educação Inclusiva: uma breve reflexão sobre avanços no Brasil após a Declaração de Salamanca. Rev. Católica, Uberlândia, v.1, n.2, p.265-274, 2009.

REIS, M.X.S; EUFRÁSIO, D.A.; BAZON, F.V.M. A formação do professor para o ensino superior: prática docente com alunos com deficiência visual. Educação em Revista, Belo Horizonte, v.26, n.1, p.111-130, 2010.

RUSSO, R.C.T.; COUTO, T.H.A.M.; VAISBERG, T.M.J.A. O imaginário coletivo de estudantes de educação física sobre pessoas com deficiência. Psicologia \& Sociedade, Campinas, v.21, n.2, p.250-255, 2009.

SANT’ANA, I.M. Educação inclusiva: concepçôes de professores e diretores. Rev. Psicologia em Estudo, Maringá, v.10, n.2, p.227-234, 2005.

SANTUÁRIO, A.A.; CAZALES, Z.N. Inclusión, equidade y cohesión social em las políticas de educación superior em México. Revista Mexicana de Investigación Educativa, México, v.19, n.60, p.213-239, 2014.

SIQUEIRA, I.M.; SANTANA, C.S. Propostas de acessibilidade para a inclusão de pessoas com deficiência no ensino superior. Rev. Bras. Educ. Espec., Marília, v.16, n.1, p.127-136, 2010.

SQUARCINI, C.F.R.; ESTEVES, A.M. Cronobiologia e inclusão de pessoas cegas: do biológico ao social. Rev. Bras. Educ. Espec., Marília, v.19, n.4, p.519-530, 2013.

STILLWELL, S.B. et al. Searching for the Evidence. Strategies to help you conduct a successful search. American Journal Nursing, v.110, n.5, p.41-47, 2010.

ZÚNIIGA, S.P.A.; MARTÍNEZ, V.G.; IZQUIERDO, J. La inclusion educative de ciegos y baja vision em el nivel superior: um studio de caso. Sinética Revista Electrónica de Educación, México, n.39, p.1-21, 2012.

Recebido em: 07/10/2015

Reformulado em: 02/05/2016

Aprovado em: 09/05/2016 